\title{
Head of the Class: John R. Wible's Transformative Insights Into Mammalian Craniodental Anatomy
}

\author{
Guillermo W. Rougier ${ }^{1} \cdot$ Timothy J. Gaudin $^{2} \cdot$ Darin A. Croft ${ }^{3}$
}

( ) The Author(s), under exclusive licence to Springer Science+Business Media, LLC, part of Springer Nature 2021

Early explorers faced in the Americas a world that could not be easily captured within the limits of the vocabulary and experience of contemporary European society. The seemingly endless geography of the continent, its people, and its animals needed new names to be intelligibly incorporated into languages that drew heavily from the experiences of the expansive and distant Roman Empire and its perpetuation in the learned ecclesiastic circles. The study, use, and above all, potential exploitation of the American bounty could not be accurately evaluated and arranged without enough linguistic precision to minimize misunderstanding. Some names, like Hispaniola Island, were completely divorced from the local traditions and solely reflected that of the intruders. In other cases, like Manhattan, precontact names were adopted with various degrees of success and rigor. Plant and animal names fared with similar mixed success in their integration into the common and scientific literature of the West. While raccoon, opossum, and caribou telegraph their native origin, others like the Spanish "nutria" (for the rodent Myocastor) and "comadreja" (for marsupial opossums like Didelphis) refer to putative (and erroneous) European counterparts (the otter Lutra and the weasel Mustela, respectively). Although these comparisons between European and American natural

Guillermo W. Rougier

guillermo.rougier@louisville.edu

Timothy J. Gaudin

Timothy-Gaudin@utc.edu

Darin A. Croft

dcroft@case.edu

1 Department of Anatomical Sciences and Neurobiology, University of Louisville, Louisville, KY, USA

2 Department of Biology, Geology, and Environmental Science (Department 2653), University of Tennessee at Chattanooga, 615 McCallie Avenue, Chattanooga, TN 37403-2598, USA

3 Department of Anatomy, Case Western Reserve University School of Medicine, 10900 Euclid Ave, Cleveland, OH 44106-4930, USA history were based on superficial similarities such as general shape, feeding habits, size, and color, they generally served our ancestors well and continue to be appropriate today for most practical uses. Nevertheless, a deeper understanding is necessary in the scientific realm; similarity only takes us so far, particularly if we are to unravel phylogenetic relationships or tackle the knotty evolutionary history of complex character systems. At a more detailed level of resolution, we enter the world of characters, character states, homology, optimization, definition, diagnosis, and phylogeny, which are the technical tools used by the evolutionary biologist to ultimately establish identity. It is through this elusive underlying "sameness" amidst bewildering biological diversity that we recognize the unifying power of the most fundamental biological relationship: the unbroken ancestor-descendant chain that ties us to reptiles, fishes, plants, and microbes as we go back further and further in time.

In this Journal of Mammalian Evolution (JME) volume, we celebrate Dr. John R. Wible (Fig. 1), who has been an intrepid explorer of mammalian anatomy for more than three decades. Like explorers of the Americas, he encountered a variety of previously unrecognized structures during his investigations and was faced with the question of how to name and describe them. Fortunately for us - and the field of comparative anatomy as a whole - John's detailed and logical approach has resulted in a nomenclatural framework and a variety of characters and character states that will be an enduring legacy for generations to come.

John served as the editor-in-chief of the JME for 14 years (2007-2021) and did a monumental job making the JME one of the leading journals of mammalian evolutionary research. He has been a steadfast supporter of the journal from its inception-he co-authored an article in its inaugural issue (see Zeller et al. 1993) —and has contributed handsomely to the journal's output ever since. John read and edited every manuscript that the journal published during his 14-year tenure, a Herculean task. However, given his remarkable attention to detail, his efforts insured a uniformly 


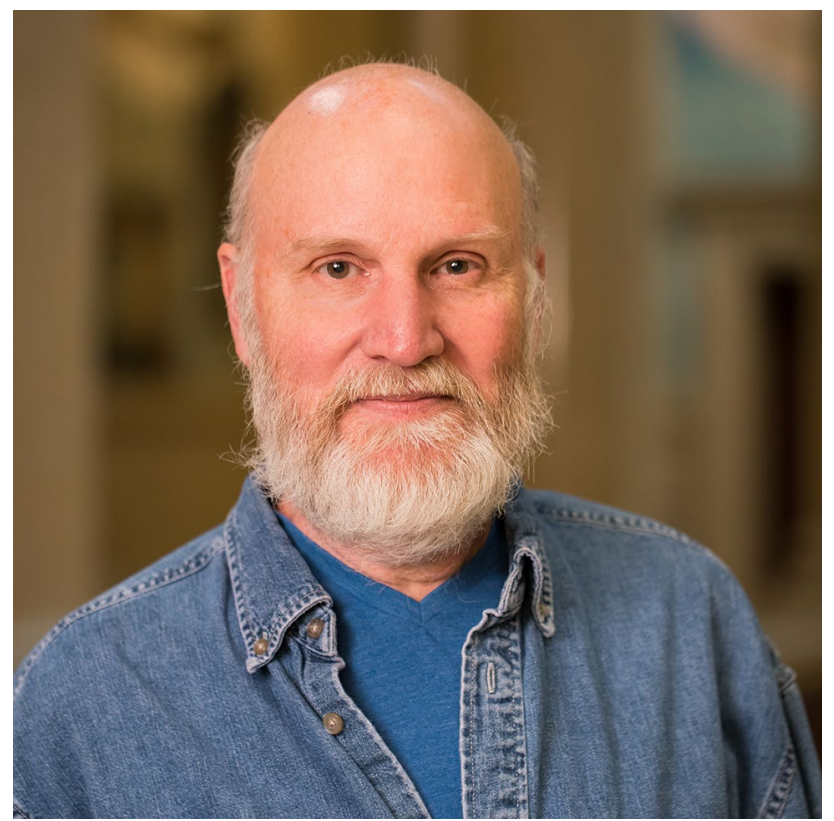

Fig. 1 John R. Wible, courtesy of the Carnegie Museum of Natural History

high publication quality, which, along with the breadth of his editorial vision, has resulted in the journal's steady rise in stature (and in citation indices). But in addition to John's impact as editor-in-chief of the JME, we want to highlight John's transformative and lasting influence in the field as a prolific and insightful scientist.

The business of morphology and systematics is to offer a series of logically linked hypotheses of character transformation and phylogeny that best explain patterns of anatomical variability, and it is safe to say that John has done it better, more often, and at greater length than any contemporary colleague. John has been the explorer of mammalian variation, describing characters and character combinations previously unknown; John has been the interpreter, establishing the primary homologies of the features he observed using the general framework of mammalian evolution; and John has been the tester of those inferences in a phylogenetic context. If we add the fact that he has gone hunting for fossils in the field and for surprises in museum collections, including the one he oversees at the Carnegie Museum of Natural History, it is hard to imagine an area of morphological expertise John has not practiced with uncanny and transformative ability. But even more than this, John is justly famous for the extremely detailed and insightful work he has produced on the craniodental anatomy of extant and extinct mammals. His monographs encompass extant marsupials and placentals, extinct members of both groups, and a smattering of extinct Mesozoic taxa (e.g., Wible 2003, 2007, 2008, 2009; Wible and Rougier 2000, 2017; Wible and Gaudin 2004). These are definitive works, not because they cannot be improved as the comparative framework changes (e.g., phylogenetic inference depends on sampling, which steadily improves, and new methods of analysis are continually being implemented) but because of his sensible interpretation of anatomy, his didactic exposition, and the vast scope of comparisons that are at the core of his work. John has created a refined language to discuss morphology, distilled mammalian cranial variability into a set of testable hypotheses about character transformations, and provided the field of comparative anatomy with an enduring framework for rigorously evaluating these and other hypotheses. He has been the "name giver" in our field, our guide in the labyrinth of mammalian morphology and systematics (both literally and figuratively!). That level of scholarship is timeless.

John's background is atypical, comfortably straddling the universe of soft tissue anatomy afforded by the study of extant mammals and the surprising diversity and plain strangeness often presented by fossilized early mammals and archaic relatives. It was not always that way. He pursued his Anthropology A.B. and M.A. at Cornell and NYU, respectively, then earned his Ph.D. in the Anatomy Department at Duke University. John left his mark at Duke, where he was the unofficial master chef at the Anatomy Department's Annual Pig Roast, rising at dawn to dig the pit with comrade graduate students (Schweitzer 2021, pers. comm.). Apparently, his kitchen prowess gained him lodging and gratitude from faculty and friends at Duke (and later at the University of Louisville), even if they were not always successful in all attempts at procuring the next meal (Bickford 2021, pers. comm.).

Under the tutelage of Matt Cartmill at Duke, John focused on vascular evolution of eutherians, resulting in an influential thesis: "The ontogeny and phylogeny of the mammalian cranial arterial pattern" (Wible 1984). In this work, he made extensive use of the embryological collections at Duke. The need to broaden the comparative sampling of mammalian embryos served as a segue for extended stays in Germany and the study of embryological collections all over Europe. In the process, he became fluent in German; John's deep appreciation and knowledge of the German morphological tradition has been central not only to his career but also for the rest of us. He has served as a translator of sorts: a (re)discoverer, archivist, and publicist for those of us hopelessly attempting to approach the standards John has established in the field.

These early years established John as a talented anatomist and morphologist with a solid knowledge of the basicranial anatomy of Recent mammals, and fossils were not yet central to his work. That changed after Dr. James (Jim) Hopson at the University of Chicago was fortunate enough to recruit John as a postdoctoral researcher. At the time, Jim was one of the leading paleontological figures on early mammals and their earlier relatives. Together, 
the two integrated paleontological and neontological evidence in an unprecedented manner in the field. Papers like "Basicranial evidence for early mammalian phylogeny" (Wible and Hopson 1993) and "Homologies of the prootic canal in mammals and non-mammalian cynodonts" (Wible and Hopson 1995) are watershed works. John's insightful and detailed work opened up a whole new set of character systems for phylogenetic use: the braincase, ear region, and neurovascular distributions. This happened at the right time, as cladistics was rapidly becoming mainstream, and there was a rekindled interest in phylogenetic research. These character systems are now routine implements in the toolbox of anyone attempting to unravel the Gordian knot of mammalian relationships. The extensive use of soft tissue inference in the study of fossils and the advancement of broad, guiding hypotheses of homology are characteristic trademarks of John's work - as well as a sophisticated descriptive prose at the service of a rational overarching plan. His attention to detail and calculating, careful planning appear to have been character traits achieved early in his development (MacPhee 2021 pers. comm.) and were critical influences in the early development of the careers of two of the present authors (GR and TG) as well as a number of our contemporaries.

From Chicago, John went to the University of Louisville, where he taught human anatomy for about ten years as a tenured faculty member. There was no natural history museum in Louisville and therefore no research collections, which encouraged John to become involved in a variety of collaborative projects in Europe, South America, and the USA. One of those collaborations was with Michael J. Novacek (Wible and Novacek 1988), then a recent hire at the American Museum of Natural History (AMNH) in New York. A few years later, Mike led the renewed exploration of the Late Cretaceous beds of Mongolia by the AMNH. Those expeditions were wildly successful (Novacek 1997), resulting in a trove of stunningly beautiful Cretaceous mammals in need of description. John, Mike, and their students worked to tackle the glut of new material, producing the first comprehensive cladistic analyses for many of those taxa as well as the first extensive monographs describing their anatomy (Wible and Rougier 2000; Wible et al. 2004, 2009). Those were transformative years for the study of early mammals. A superb collection and John's talent resulted not only in a detailed record of a host of new mammals but also, perhaps even more importantly, the establishment of broad statements of synapsid craniodental homology stretching beyond the confines of Mammalia. We can recall astonished colleagues, skeptically pondering the results of adding 50 or 70 new basicranial characters to a narrative that had previously been scripted based primarily on dental evolution.

From the Anatomy Department at Louisville, John moved to the Section of Mammals at the Carnegie Museum of
Natural History in Pittsburgh, in 1998. He has been the head of the Section of Mammals since then, with an extensive collection under his care. This happy circumstance amounted to putting a kid in charge of a candy store! Since then, John has produced a long series of (long) monographs on the craniodental anatomy of Recent mammals, including marsupials, solenodons, treeshrews, bats, xenarthrans, carnivorans, rodents, the aardvark, and so on. He has single handedly set a new standard for morphological research. These publications are commanding references for anyone interested in mammalian anatomy.

John has also been a generous mentor and an example to students and colleagues. He has always been willing to spend long hours going over complex issues, be it human anatomy, puzzling fossils, or the technical aspects of photography and CT scanning. As a colleague, arguing a scientific problem with John is an exercise in scholarly discourse; he will make his case, listen to yours, and then offer a new take on the issue. He may or may not agree, but reasonable compromise is always within reach and not a cause for tension.

The handful of papers we have collected in John's honor do not do justice to the breadth of his research, and we can only aspire to achieve a similar depth of description and analysis. This collection should be taken as an affectionate, grateful, and admiring token of recognition to a gifted friend who has transformed what we do as scientists. It includes eight articles authored by friends, colleagues, collaborators, and mentees that span a taxonomic range nearly as great as that traversed by John in his explorations of the mammalian evolutionary tree. All of them build on detailed anatomical descriptions of craniodental morphology published by John during his career:

The paper by Davis et al. entitled "Mammalian petrosals from the Upper Jurassic Morrison Formation (Utah, USA) reveal non-canonical evolution of middle and inner ear characters," describes new specimens from the seemingly inexhaustible Morrison Formation of the American West, which continues to produce fossil surprises. In this case, it is a set of mammalian petrosals showing a noncanonical ear morphology, including a full cochlear turn and traits that indicate a middle ear with many plesiomorphic character states. This is the earliest occurrence of a coiled cochlea and, intriguingly, these specimens probably do not pertain to any mammalian taxon currently known from the Morrison.

Rougier et al.'s manuscript, entitled "New specimens of Reigitherium bunodontum from the Late Cretaceous La Colonia Formation, Patagonia, Argentina and meridiolestidan diversity in South America", describes recently collected specimens that resolve long standing uncertainties about the dentition of this enigmatic mammal. The unusual dental morphology can be seen as an extreme modification of the primitive dryolestoid pattern that is adapted to a more 
herbivorous diet. Reigitherium, Mesungulatum, and relatives represent one of the earliest herbivorous radiations of stem therian mammals.

The study of Krause et al., "New skull material of Taeniolabis taoensis (Multituberculata, Taeniolabididae) from the early Paleocene (Danian) of the Denver Basin, Colorado", brings this classic multituberculate taxon into the twentyfirst century. The detailed descriptions and wonderful CT images of new and impressively complete specimens that form the foundation of this contribution firmly solidify the position of Taeniolabis as one of the best known multituberculates and are certain to play an important role in future studies of this diverse group of archaic mammals.

Giannini et al., in their work entitled "The cranial morphospace of extant marsupials," combine a detailed morphometric analysis of adult skulls from the whole diversity of living marsupials with a phylogenetic approach to examine how the marsupial skull has evolved. They document limited convergence between South American and Australian taxa but more extensive convergence within Australodelphia, particularly among grazing marsupials. They also note voids in the morphospace created by extinction and suggest that adding fossils to this analysis could greatly enhance our understanding of marsupial cranial evolution.

The paper by Shelley et al., "Petrosal anatomy of the Paleocene eutherian mammal Deltatherium fundaminis (Cope, 1881)", presents very detailed descriptions and illustrations of the basicranial anatomy of this puzzling mammal. The authors use the new data on Deltatherium to conduct comprehensive comparisons with contemporaneous members of Arctocyonidae, Pantodonta, Tillodontia, and other Paleocene mammals and note the great potential this novel information has for clarifying the evolutionary relationships of Deltatherium in future phylogenetic analyses.

In the study conducted by Gaudin et al., entitled "Osteological anomalies in the extant two-toed sloth Choloepus, and the narial anatomy of extinct and extant sloths," the authors examine a variety of unusual structures associated with the bony external narial aperture in some specimens of two-toed sloths. They use these structures as a basis to try to understand the homology of similar structures in a variety of representatives from the diverse radiation of extinct terrestrial sloths so characteristic of the late Cenozoic of the Americas. They note that their interpretations are limited by preservational issues but suggest that narial anatomy is a fruitful area for future study in sloths.

Juman et al. address the question of intraspecific versus interspecific morphological variation in treeshrews in their study "Skeletal variation and taxonomic boundaries in the Pen-tailed Treeshrew (Scandentia, Ptilocercidae: Ptilocercus lowii Gray, 1848)." Using osteological data from the skull and innominate, they document little to no morphometric overlap between the two currently recognized subspecies of
Ptilocercus lowii and suggest that additional data may eventually support their recognition as separate species, a finding that would have important implications for conservation.

The contribution by Croft et al., "New chinchillid rodents (Hystricognathi: Caviomorpha) from northern Chile and Bolivia fill a 17-million-year gap in the pan-chinchilline fossil record", names two new Miocene species that are more closely related to modern chinchillas and mountain viscachas than they are to the plains viscacha (Lagostomus maximus). The new species from northern Chile, Miochinchilla surirense, is represented by well-preserved craniodental remains and limited postcranial remains that provide a remarkably detailed understanding of the anatomy of this early Miocene taxon.

It is unthinkable to find a current paper on early mammals or mammalian cranial anatomy that will not refer to John's work, as evidenced by the contributions to the present volume. We as editors are liable to be accused of partiality, and perhaps rightly so given how much we admire and appreciate John's enormous body of work, and how much we have enjoyed his friendship and comradery over the years. However, his steady guardianship of the Journal of Mammalian Evolution, his care of the Section of Mammals at the Carnegie Museum, and his sheer brilliance have transformed mammalian evolutionary studies and certainly merit this celebration of his achievements. We are excited to see what he has in reserve for us and our field in the coming years.

\section{Appendix: Personal Communications}

Bickford (2021): I remember some fabulous dinners he hosted as a graduate student at Duke, as well as here in Louisville. There were also other adventures. During a trip to Mount Ranier, we camped near a lake and tried to catch some fish. We didn't have any bait, so we used some chunks of cheese. None of us could catch a thing, but next to us a little girl about 3 or 4 years old was very successful and caught a nice big fish. As her excited dad was pulling out the hook he exclaimed, "this fish is full of cheese!".

MacPhee (2021): John and Basketball, 1979. We all know John Wible as a remarkable morphologist who writes papers that are characterized by both their great length as well as their great perception. How did he become so good at what he does? His education at Cornell and Duke may have helped, but I think that what really honed his skills as an astute observer was his career as a basketball handicapper during his grad student days. In the early 1980s, just as now, Duke was a cult center for college basketball. Every March, devotees in the Department of Anatomy would gather in small conclaves to pour over mysterious charts and similar arcana in order to prophecy who among that year's contending teams would end up as secular gods, aka the Final 
Four. Among the many who claimed special occult powers in this regard there was only one who consistently delivered spot-on prognostications...Wible. Now, there was money involved, but not very much, and John was of course in it for the glory. It may well be asked what the ability to call wins in basketball has to do with writing expert technical papers in anatomy and phylogeny. The answer is probably not very much, except that you can't be good at either unless you have not only the determination to uncover the facts that really matter as well as the insight to apply them in a way that solves the puzzle at hand. In a nutshell, that's John's gift, and it has won him the respect and admiration of his colleagues for decades.

Schweitzer (2021): Knowing his propensity for cooking, when he asked if he could live with us for several weeks after graduate school, we enthusiastically said "yes" but only if he would cook for us! He was an excellent chef who specialized in Pakistani cooking, and I still use his recipes today.

\section{References}

Novacek MJ (1997) Dinosaurs of the Flaming Cliffs. Anchor

Wible JR (1984) The ontogeny and phylogeny of the mammalian cranial arterial pattern. Ph.D. dissertation, Duke University, Durham, $704 \mathrm{pp}$

Wible JR (2003) On the cranial osteology of the short-tailed opossum Monodelphis brevicaudata (Didelphidae, Marsupialia). Ann Carnegie Mus 72:137-202

Wible JR (2007) On the cranial osteology of the Lagomorpha. Bull Carnegie Mus Nat Hist 39:213-234. https://doi.org/10.2992/01459058(2007)39[213:OTCOOT]2.0.CO;2
Wible JR (2008) On the cranial osteology of the Hispaniolan solenodon, Solenodon paradoxus Brandt, 1833 (Mammalia, Lipotyphla, Solenodontidae). Ann Carnegie Mus 77:321-385

Wible JR (2009) The ear region of the pen-tailed treeshrew, Ptilocercus lowii Gray, 1848 (Placentalia, Scandentia, Ptilocercidae). J Mamm Evol 16:199-233 https://doi.org/10.1007/s10914-009-9116-Z

Wible JR, Gaudin TJ (2004) On the cranial osteology of the yellow armadillo Euphractus sexcinctus (Dasypodidae, Xenarthra, Placentalia). Ann Carnegie Mus 73:117-196

Wible JR, Hopson JA (1993) Basicranial evidence for early mammal phylogeny. In: Szalay FS, Novacek MJ, McKenna MC (eds) Mammal Phylogeny: Placentals. Springer-Verlag, New York, pp 45-62

Wible JR, Hopson JA (1995) Homologies of the prootic canal in mammals and non-mammalian cynodonts. J Vertebr Paleontol 15:331-356

Wible JR, Novacek MJ (1988) Cranial evidence for the monophyletic origin of bats. Am Mus Novitates 2911:1-19

Wible JR, Rougier GW (2000) Cranial anatomy of Kryptobaatar dashzevegi (Mammalia, Multituberculata), and its bearing on the evolution of mammalian characters. Bull Am Mus Nat Hist 247:1-124

Wible JR, Rougier GW (2017) Craniomandibular anatomy of the subterranean meridiolestidan Necrolestes patagonensis Ameghino, 1891 (Mammalia, Cladotheria) from the early Miocene of Patagonia. Ann Carnegie Mus 84:183-252. https://doi.org/10.2992/007. 084.0302

Wible JR, Novacek MJ, Rougier GW (2004) New data on the skull and dentition in the Mongolian Late Cretaceous eutherian mammal Zalambdalestes. Bull Am Mus Nat Hist:1-144

Wible JR, Rougier GW, Novacek MJ, Asher RJ (2009) The eutherian mammal Maelestes gobiensis from the Late Cretaceous of Mongolia and the phylogeny of Cretaceous eutherians. Bull Am Mus Nat Hist:1-123

Zeller U, Wible JR, Elsner M (1993) New ontogenetic evidence on the septomaxilla of Tamandua and Choloepus (Mammalia, Xenarthra), with a reevaluation of the homology of the mammalian septomaxilla. J Mamm Evol 1:31-46 